\title{
Magnitud del riesgo por accidentes con objetos cortopunzantes en la consulta odontológica*
}

Magnitude of Risk for Accidents with Sharps in the Dental Practice

Magnitude do risco para acidentes com perfurocortantes na prática odontológica

Fecha de recepción: 25-10-2018 | Fecha de aceptación: 14-03-2019

\section{Francisco CaZARes de León}

Universidad de Monterrey, Monterrey, Nuevo León, México. fclsalud@gmail.com; http://orcid.org/0000-0002-0481-8956

\author{
Miriam Alveza Treviño TAMÉz \\ Universidad Autónoma de Nuevo León, Monterrey, Nuevo León, México. alveza62@gmail.com; \\ http://orcid.org/0000-0001-5403-3949
}

\section{DAVID ERnesto Soto GÁMEZ}

Universidad Autónoma de Nuevo León, Monterrey, Nuevo León, México. david.soto@saludnl.gob.mx; https://orcid.org/0000-0001-8669-6632 
Universidad Autónoma de Nuevo León, Monterrey, Nuevo León, México. maria.sanchez@saludnl.gob.mx; https://orcid.org/0000-0002-0532-8094

*Artículo de investigación original

Correspondencia: fclsalud@gmail.com; alveza62@gmail.com; david.soto@saludnl.gob.mx; maria.sanchez@saludnl.gob.mx

doi: https://doi.org/10.11144/Javeriana.uo38-80.mrao

Cómo citar: Cázares de León F, Treviño Taméz MA, Soto Gámez DE, Sánchez Márquez MC. Magnitud de riesgo por accidentes con objetos cortopunzantes en la consulta odontológica. Univ Odontol. 2019 ene-jun; 38(80). https://doi.org/10.11144/Javeriana.uo38-80.mrao

\section{RESUMEN}

Antecedentes: El personal del área de la salud está constantemente expuesto a sangre y fluidos provenientes de los pacientes durante su jornada laboral. Por lo tanto, el personal de odontología corre el riesgo de contraer enfermedades infecciosas. Objetivo: Conocer la frecuencia del riesgo laboral por objetos punzocortantes en odontólogos de primer nivel de atención de los Centros de Salud urbano y rural de los Servicios de Salud de Nuevo León Monterrey Nuevo León, México. Métodos: diseño del estudio no experimental, descriptivo, transversal y prospectivo. Población de estudio: odontólogos aplicativos de los Servicios de Salud de Nuevo León con un muestreo 
probabilístico 108 odontólogos. Se utilizó un cuestionario diseñado con 12 preguntas relacionadas con los accidentes punzocortantes, con una confiabilidad de un alfa de Cronbach de .832 . Resultados: el $38.8 \%$ de los masculinos informó haber presentado accidente laboral y femeninas el $67.2 \%$ señalaron haber sufrido un accidente con punzocortante. En relación al conocer si habían sufrido algún accidente por objetos punzocortantes, solo el $59.3 \%$ lo reportó y un 40.7 \% no había sufrido accidente; un $49 \%$ si recibió capacitación en bioseguridad y un $51 \%$ no ha recibido capacitación. Conclusión: Con base a estos resultados podemos concluir que aún falta por mejorar las capacitaciones y ampliar la cobertura de capacitación a los odontólogos en materia de normativas de bioseguridad y manejo de residuos peligrosos biológicos infecciosos, así como actualizar el conocimiento de infecciones transmitidas por objetos punzocortantes.

\title{
Palabras clave
}

accidente; bioseguridad; capacitación; objeto cortopunzante

\section{Áreas temáticas}

administración en salud; odontología; salud ocupacional

\begin{abstract}
Background: The staff of the health area is constantly exposed to blood and / or fluids coming from patients during their workday. Therefore, dentistry personnel run the risk of contracting infectious diseases. Purpose: To know the frequency of occupational risk due to sharp objects in top-level dentists of the urban and rural Health Centers of the Health Services of Nuevo León.
\end{abstract}


Methods: design of the non-experimental, descriptive, cross-sectional and prospective study. Study population: applicative dentists of the Health Services of Nuevo Leon with a probabilistic sampling 108 of dentists. A questionnaire designed with 12 questions related to sharps accidents with a reliability of a Cronbach's alpha of .832 was used. Results: $38.8 \%$ of the men reported having presented an accident at work and $67.2 \%$ of the women reported having suffered an accident with a sharp cut. In relation to knowing if they had suffered an infection due to an accident by sharp objects, $59.3 \%$ had suffered an accident and $40.7 \%$ had not suffered an accident; $49 \%$ were trained in biosecurity and $51 \%$ have not received training. Conclusion: Based on these results we can conclude that there is still a need to improve the training and expand the coverage of training to the dentist in matters of biosafety regulations and management of infectious biological dangerous wastes as well as to update the knowledge of puncture-borne infections.

\title{
Keywords
}

accidents; biosecurity; sharp objects; training

\section{Thematic fields}

dentistry; health care management; occupational health

\begin{abstract}
ABSTRATO
Antecedentes: A equipe da área de saúde é constantemente exposta ao sangue e / ou fluidos provenientes dos pacientes durante o dia de trabalho. Portanto, o pessoal de odontologia corre o risco de contrair doenças infecciosas. Objetivo: Conhecer a frequência do risco ocupacional por
\end{abstract}


objetos pontiagudos em dentistas de nível superior dos Centros de Saúde urbanos e rurais dos Serviços de Saúde de Nuevo León. Métodos: delineamento do estudo não experimental, descritivo, transversal e prospectivo. População do estudo: dentistas aplicativos dos Serviços de Saúde de Nuevo León com amostragem probabilística 108 de cirurgiões-dentistas. Foi utilizado um questionário elaborado com 12 questões relacionadas aos acidentes com perfurocortantes, com confiabilidade de um alfa de Cronbach de 0,832. Resultados: 38,8\% dos homens relataram ter sofrido acidente no trabalho e $67,2 \%$ das mulheres relataram ter sofrido acidente com um corte acentuado. Em relação a saber se sofreram infecção por acidente por objetos pontiagudos, 59,3\% sofreram acidente e 40,7\% não sofreram acidente; $49 \%$ foram treinados em biossegurança e 51\% não receberam treinamento. Conclusão: Com base nesses resultados, podemos concluir que ainda há uma necessidade de melhorar o treinamento e ampliar a cobertura do treinamento para o dentista em questões de regulamentos de biossegurança e gestão de resíduos infecciosos biológicos perigosos, bem como atualizar o conhecimento sobre punção. infecções suportadas.

\section{Palavras-chave}

acidentes; biossegurança; objetos punzantes; treinamento

\section{Campos temáticos}

gestão de saúde; odontologia; saúde ocupacional 


\section{INTRODUCCIÓN}

El personal del área de la salud está constantemente expuesto a sangre y/o fluidos provenientes de los pacientes durante su jornada laboral. Por lo tanto, el personal de odontología corre el riesgo de contraer enfermedades infecciosas (1-3).

La aparición de enfermedades como el VIH-SIDA y de la Hepatitis B y C, entre otras enfermedades infecciosas, el desarrollo de estas y el conocimiento de las vías de transmisión, hacen que la exposición a objetos punzocortantes sea un peligro potencial entre los trabajadores de la salud, llegando a generar incapacidades laborales temporales o permanentes. Los objetos punzocortantes son probablemente uno de los mayores riesgos ocupacionales entre los prestadores de servicios de salud que manejan desechos $(3,4)$ esto por el daño que pueden causar.

El personal de salud con mayor riesgo de sufrir algún accidente laboral (pinchazo con aguja, cortadura) son las enfermeras, cirujanos, personal de laboratorio y los odontólogos, como lo confirma la revisión de Collins y Kennedy (5). El $48.5 \%$ de las enfermeras reportaron accidente laboral por pinchazo y el $17.9 \%$ fue el personal de laboratorio (5), En otro estudio de Adegbaye el $100 \%$ de los odontólogos habían sufrido algún accidente y un $81 \%$ de los cirujanos han sufrido accidentes con punzocortantes (6). En el estudio de Junco y colaboradores (4), un $28.2 \%$ de los trabajadores sufrieron al menos una punción o lesión, predominando enfermería, técnicos y médicos. 
En el año 2000 se estimaba que en Estados Unidos ocurrían entre 600000 y 800000 pinchazos por agujas, aunque la mitad no se reporta (4). Por otro lado, Collins en su estudio de revisión reportó que entre los más de 20 microorganismos patógenos transmitidos en los objetos punzocortantes contaminados los que constituyen la mayor preocupación están el virus de la hepatitis B y C y el de VIH (5).

De estos el VIH continúa como uno de los problemas de salud pública a nivel mundial con 36.7 millones de personas infectadas por el VIH hasta finales del año 2016, esto según los reportes de la Organización Mundial de la Salud (OMS) (7), y que ha generado aproximadamente 25 millones de fallecimientos en todo el mundo. Ante esto es de resaltar una buena noticia que en algunos países de Asia, América Latina y África el número de infecciones por VIH ha disminuido. En México hasta el 2014 se habían registrado 223,995 casos (3).

Con respecto a los casos de Hepatitis B, la OMS estimó que en para el 2017 había 257 millones de personas infectadas crónicamente con este virus, y que en el 2015 provocó 887,000 muertes, la mayoría por complicaciones como cirrosis o carcinoma hepatocelular (8). Estas infecciones por estos dos virus representan un importante riesgo laboral para los profesionales sanitarios, como lo reflejan estos datos, ya que la transmisión del virus del SIDA y con mayor frecuencia la hepatitis B y C, por medio de las lesiones originadas por agujas contaminadas con sangre ponen en riesgo su salud día con día. Siendo los trabajadores que laboran en los centros de salud y quienes manipulan desechos médicos y fluidos corporales (4). 
Con estos antecedentes es fundamental la bioseguridad en el personal estomatológico, ya que esta representa un componente vital del sistema de garantía de calidad, orientando la bioseguridad a conductas que disminuyan el riesgo del profesional de la salud a adquirir infecciones en su ambiente laboral (8).

Y aunque en México se están realizando esfuerzos por controlar ésta situación es todavía necesario fomentar la cultura de la prevención, concientizando a los trabajadores de los centros de salud de primer nivel, para que conozcan los riesgos a los que se exponen, así como el de conocer los protocolos a seguir en caso de algún accidente (9). Un estudio en Cuba aplicado a odontólogos demostró conocimientos insuficientes de la conducta a seguir ante un accidente ocupacional y medianamente el conocimiento sobre las medidas de protección (10).

Los profesionales dedicados al cuidado de la salud específicamente los trabajadores de la salud están expuestos a diversos riesgos profesionales tales como: químicos peligrosos, riesgos ergonómicos al momento de movilizar al paciente, falta de personal, rotación de turnos, adicionalmente sufren de estrés en su vida diaria y en su ambiente laboral. ${ }^{10}$ Conjuntamente a los riesgos antes mencionados, los trabajadores de la salud se enfrentan a riesgos biológicos y/o microorganismos transmitidos por contacto de vías aéreas o vías sanguíneas, como el virus de la hepatitis o VIH, entre otras enfermedades (1,3,7 y 8$)$.

De acuerdo a la literatura médica internacional los derivados de accidentes con objetos punzocortantes son los más frecuentes de los centros hospitalarios, como lo es el primer caso reportado en 1847 por Ignaz Senmmoweis, donde se involucra un accidente con material 
punzocortante durante una manipulación de instrumentos en una autopsia. En 1981 surgieron los primeros casos de SIDA, causando mayor preocupación sobre todo entre los trabajadores de la salud, al reportarse un trabajador de la salud después de una exposición percutánea a VIH en África.

El virus de la hepatitis B es el de mayor riesgo de infección para los trabajadores de la salud, por la prevalencia de la enfermedad en la población mundial. Son las agujas de sutura y los bisturís los instrumentos que causan heridas con mayor frecuencia entre los profesionales de la salud.

Un estudio de Gutiérrez y cols. En trabajadores del primer nivel de atención en Perú en el 2008 un $34 \%$ habría sufrido alguna herida con punzocortantes a pesar de que un $66 \%$ recibió capacitación en bioseguridad (11). Por lo que la razón principal de este estudio es el de determinar la magnitud de los accidentes por punzocortantes en los odontólogos de los centros de salud de las 8 jurisdicciones del Estado de Nuevo León, para que al conocer la frecuencia de los accidentes laborales se pueda reforzar las medidas preventivas por medio de capacitaciones con temas de bioseguridad y así disminuir las probabilidades de accidentes laborales por objetos punzocortantes, contraer infecciones y las incapacidades $(9,12)$.

\section{Objetivo general}

Conocer la frecuencia del riesgo laboral por objetos punzocortantes en odontólogos de primer nivel de atención de los Centros de Salud urbano y rural de los Servicios de Salud de Nuevo León.

\section{Objetivos específicos}


- Identificar si ha sufrido accidentes por objetos cortopunzantes a través de un cuestionario autoadministrado.

- Comparar la frecuencia de accidentes con objetos punzocortantes por género.

- Conocer si ha sufrido alguna infección por un accidente por objetos punzocortantes

- Observar si tiene capacitación de bioseguridad en el consultorio.

\section{Variables operacionales}

Variable dependiente: accidentes. Variable independiente: objetos punzocortantes.

\section{MATERIALES Y MÉTODOS}

Diseño del estudio: Observacional, descriptivo y transversal.

Población de estudio o unidad de análisis: odontólogos aplicativos de los Servicios de Salud de Nuevo León.

Temporalidad: del mes de marzo al mes de abril del 2018.

Ubicación espacial: consultorios dentales de los Centros de Salud urbanos y rurales de las 8 Jurisdicciones de los Servicios de Salud de Nuevo León.

Criterios de inclusión: odontólogos aplicativos de base, contrato y odontólogos pasantes que estén dando consulta dental en el primer nivel de atención.

Criterios de Exclusión: odontólogos de base o contrato que no estén o hayan estado en el nivel aplicativo de atención de primer nivel de odontología.

Criterios de Eliminación: quienes hayan contestado incorrectamente o incompletos los cuestionarios. 
Muestra: muestreo probabilístico 108 odontólogos de base, contrato y pasantes, de un censo total de 150 con un nivel de confianza de $99 \%$, de una población finita, ya que se conoce el censo total de los odontólogos.

\section{Instrumento de recolección}

Se utilizó un cuestionario diseñado con cuatro preguntas para variables de tipo socio-demográfico así como doce preguntas relacionadas con los accidentes punzocortantes y opciones de respuesta cerrada, donde estos doce ítems tuvieron una confiabilidad de un alfa de Cronbach de .832 .

\section{Propuesta de análisis estadístico}

Se utilizó estadística descriptiva con análisis de frecuencia, porcentajes, medidas de tendencia central y dispersión, para describir a la población con respecto a las variables de interés no categóricas. Posteriormente se utilizó la prueba de chi cuadrada de Pearson para la asociación de variables nominales. Todo esto con el paquete estadístico SPSS versión 16.0.

\section{Consideraciones éticas}

El presente estudio se realizó con estricto apego a lo estipulado en la Norma técnica número 313 en el artículo 15 del Diario Oficial de la Federación en México para la presentación de proyectos e informes técnicos de investigación en las instituciones de atención en salud, sobre la manera en que se deben respetar los preceptos éticos en una investigación que se realice a seres humanos. Se respetó el anonimato de cada uno de los participantes, previo consentimiento informado firmado para participar en el presente proyecto de investigación registrado y aprobado por el Comité Estatal de Investigación en Salud de Nuevo León.

\section{RESULTADOS}


En el presente estudio de investigación con relación a accidentes laborales por objetos punzocortantes en odontología, se aplicaron 108 encuestas a cirujanos dentistas, y pasantes de cirujano dentista, de diferente edad y género, así como de tiempos laborales desiguales.

En relación a la variable edad y género se encontró que 31 (28.7 \%) pertenecen al género masculino y $77(71.3 \%)$ al femenino, con un rango mínimo de 28 años y máximo de 64 años. Los grupos etarios se agruparon de 20 a 29 años $(47.2 \%)$ de 30 a 39 años $(17.6 \%)$ de 40 a 49 años $(13.9 \%)$ de 50 a 59 años $(13.9 \%)$ y de 60 o más $(7.4 \%)$.

Con respecto a la proporción de los odontólogos que sufrieron accidente por punzocortantes se localizó, que 21 masculinos (32.8\%) informo haber presentado accidente laboral y 43 femeninas $(67.2 \%)$ señalaron haber sufrido un accidente con punzocortante.

Con relación a la antigüedad laboral se encontró que 43 encuestados tenían de 0 a 1 años de antigüedad (35.9\%) 17 de 2 a 5 años de antigüedad (14.1\%) 9 de 6 a 10 años de antigüedad (9.4 \%) 19 de 11 a 20 años de antigüedad (18.8 \%) y 20 de 20 años o más de antigüedad (21.9\%) (tabla 1).

TABLA 1

TOTAL DE LA POBLACIÓN (108) ENCUESTADA POR AÑOS DE ANTIGÜEDAD LABORAL Y EL TOTAL DEL PERSONAL QUE PRESENTO ACCIDENTE LABORAL ASÍ COMO EL TOTAL DE LAS INFECCIONES

\begin{tabular}{lccccccc}
\hline Antigüedad en & $\begin{array}{c}\text { Número de } \\
\text { la secretaria }\end{array}$ & $\begin{array}{c}\text { personas } \\
\text { encuestadas }\end{array}$ & $\begin{array}{c}\text { Porcentaje de } \\
\text { accidentados }\end{array}$ & \multicolumn{1}{c}{$\begin{array}{c}\text { Frecuencia de presentación de } \\
\text { accidentes (número de veces) }\end{array}$} & $\begin{array}{c}\text { Total de } \\
\text { infecciones del } \\
\text { personal } \\
\text { encuestado }\end{array}$ \\
\hline \hline <1 año & 43 & $35.9 \%(23)$ & $42.60 \%$ & $60 \%$ & $12.50 \%$ & $18.80 \%$ & 0 \\
2- 5 años & 17 & $14.1 \%(9)$ & $17 \%$ & $20 \%$ & $0 \%$ & $6.20 \%$ & 0 \\
6-10 años & 9 & $9.4 \%(6)$ & $6.40 \%$ & $10 \%$ & $12.50 \%$ & $18.80 \%$ & 0 \\
$11-20$ años & 19 & $18.8 \%(12)$ & $19.10 \%$ & $0 \%$ & $50 \%$ & $25 \%$ & 0
\end{tabular}




\begin{tabular}{lccccccc} 
Mas de 20 años & 20 & $21.9 \%(14)$ & $14.90 \%$ & $10 \%$ & $25 \%$ & $31.20 \%$ & 1 \\
Total & $\mathbf{1 0 8}$ & $\mathbf{1 0 0 \%}$ & $100 \%$ & $100 \%$ & $100 \%$ & $100 \%$ & $\mathbf{1 0 0 \%}$ \\
& & & & & & \\
\hline
\end{tabular}

En relación al conocer si habían sufrido alguna infección por un accidente solamente, siendo una mujer odontóloga la única. Referente al conocimiento del protocolo a seguir en caso de accidente laboral 41 (38\%) lo conocen y 67 (62\%) no lo conocen (tabla 2).

TABLA 2

TOTAL DE LA POBLACIÓN (108) ENCUESTADA POR GÉNERO QUE SUFRIÓ INFECCIÓN POR ACCIDENTE LABORAL CON OBJETOS PUNZOCORTANTES Y PROTOCOLO A SEGUIR

DESCRIPCION POR GENERO DE PERSONAL DESCRIPCION POR GENERO DE PERSONAL QUESUFRIO INFECCION POR ACCIDENTE QUE CONOCE EL PROTOCOLO A SEGUIR EN LABORAL ACCIDENTELABORAL

\begin{tabular}{|c|c|c|c|c|c|c|c|c|c|}
\hline \multirow{3}{*}{ GENERO } & \multirow{2}{*}{\multicolumn{2}{|c|}{ SI }} & \multirow{2}{*}{\multicolumn{2}{|c|}{ NO }} & \multirow{2}{*}{\multicolumn{3}{|c|}{ SI }} & \multirow[b]{3}{*}{$\%$} & \\
\hline & & & & & & & & & \\
\hline & FRECUENCIA & $\%$ & FRECUENCIA & $\%$ & FRECUENCIA & $\%$ & FRECUENCIA & & \\
\hline MASCULINO & 0 & $0 \%$ & 31 & $28.70 \%$ & 13 & $41.90 \%$ & 18 & $58.10 \%$ & $100 \%$ \\
\hline FEMENINO & 1 & $1.30 \%$ & 76 & $71.30 \%$ & 28 & $36.40 \%$ & 49 & $63.60 \%$ & $100 \%$ \\
\hline TOTAL & 1 & $0.90 \%$ & 107 & $99.10 \%$ & 41 & $38 \%$ & 67 & $62 \%$ & $100 \%$ \\
\hline
\end{tabular}

En lo que se refiere al haber sufrido un accidente por algún objeto punzocortante como pudo haber sido la aguja, la lanceta, hoja de bisturí, instrumento, vidrio o aguja de sutura, el 59.3\% (64) habían sufrido algún accidente y un $40.7 \%$ (44) no habían sufrido accidente.

Con respecto a conocer si han recibido capacitación de la norma oficial mexicana 087 que se refiere al control de los residuos peligrosos biológicos infecciosos en el consultorio médico dental, el 49 \% (53) si recibió capacitación y el 51 \% (55) no ha recibido capacitación. En relación a si conocen el protocolo de que hacer en caso de accidente un $38 \%$ (41) dijo que sí y un $62 \%$ (67) dijeron que no. 
No hubo una asociación estadísticamente significativa entre la frecuencia de accidentes con objetos punzocortantes y el género $(\mathrm{x} 2=.255)$. Tampoco hubo una asociación estadísticamente significativa entre el haber sufrido un accidente por objetos punzocortantes y haber recibido capacitación de la norma 087 (x2=.084).

TABLA

Total DE LA POBLACiÓN (108) ENCUESTADA, SOBRE El CONOCIMIENTO DE LA NORMA OFICIAL MeXICANA 087 SSNL, Y SU ASOCIACIÓN CON SUFRIR UN ACCIDENTE LABORAL POR OBJETOS PUNZOCORTANTES

\begin{tabular}{|c|c|c|c|c|c|c|}
\hline \multirow{3}{*}{$\begin{array}{l}\text { Accidente } \\
\text { laboral }\end{array}$} & \multicolumn{4}{|c|}{ Conocimiento de la norma oficial mexicana 087} & \multirow{2}{*}{\multicolumn{2}{|c|}{ Total }} \\
\hline & \multicolumn{2}{|c|}{$\mathbf{S i}$} & \multicolumn{2}{|c|}{ No } & & \\
\hline & Frecuencia & $\%$ & Frecuencia & $\%$ & Frecuencia & $\%$ \\
\hline Si & 27 & $25 \%$ & 37 & $34.20 \%$ & 64 & $59.20 \%$ \\
\hline No & 26 & $24 \%$ & 18 & $16.60 \%$ & 44 & $40.60 \%$ \\
\hline Total & 53 & $49 \%$ & 55 & $50.80 \%$ & 108 & $100 \%$ \\
\hline
\end{tabular}

\section{DISCUSIÓN}

Con respecto a los resultados establecidos en el presente estudio realizado en el 2018 con un total de 108 encuestados, todos odontólogos de base y pasantes odontólogos adscritos al Programa de Salud Bucal de la Secretaría de Salud de Nuevo León México, se pudo localizar se presentaron 64 accidentes, siendo un porcentaje de $59 \%$ superior a la media, siendo el género femenino con un $67.2 \%$ quienes han sufrido mayormente accidentes sin haber una asociación estadísticamente significativa con la prueba de chi cuadrada. Debido a que no se han reportado estudios similares en población mexicana esta investigación cobra mayor importancia en nuestro contexto pero a la vez tuvimos que comparar nuestros hallazgos con diferentes poblaciones en nuestro país. 
Queda establecido que el grupo de edad que presentó cifras promedio superior de accidentes con objetos punzocortantes fue el de 20 a 29 años de edad, tal vez debido a los años de antigüedad, siendo los de 0 a 1 año de actividad laboral quienes sufrieron mayormente accidentes con un 39.8 $\%$, datos similares a los de Collins y Kennedy donde el $48.5 \%$ de las enfermeras reportaron accidente laboral por pinchazo y el $17.9 \%$ fue el personal de laboratorio, muy distantes de los resultados de Adegbaye donde el $100 \%$ de los odontólogos habían sufrido algún accidente y un $81 \%$ de los cirujanos han sufrido accidentes con punzocortantes.

El $38 \%$ de los odontólogos encuestados mencionaron haber tenido capacitación de la Norma Oficial Mexicana SSA 087, sobre protocolos de accidente laboral muy diferente al estudio de Gutiérrez y cols. En trabajadores del primer nivel de atención en Perú donde un $34 \%$ habría sufrido alguna herida con punzocortantes a pesar de que un $66 \%$ recibió capacitación en bioseguridad, lo cual refleja la necesidad tan importante de este tipo de capacitaciones. Sin embargo en nuestro estudio no existe una asociación estadísticamente significativa entre el haber sufrido un accidente por objetos punzocortantes y el conocer la norma 087, dato relevante, ya que de acuerdo a la literatura queda establecido que se presentan más de dos millones de accidentes laborales en el mundo, esto sin tener en cuenta todos los sub registros como es el caso de nuestra investigación donde solo el $59.3 \%$ reportó haber sufrido un accidente laboral.

Los resultados de este estudio demostraron que el objeto con el que mayormente se sufrió un accidente fue la aguja dental, con un $47.2 \%$ en comparación con los otros objetos, algo similar a los estudios de Gutiérrez y cols., donde un $34 \%$ de los trabajadores de salud en el primer nivel de atención sufrieron algún accidente. Así mismo, el promedio de accidentes con aguja fue al 
momento de iniciar un procedimiento de $27 \%$ no encontrándose estudios similares para poder comparar.

Collins en su estudio de revisión reportó que entre los más de 20 microorganismos patógenos transmitidos en los objetos punzocortantes contaminados están el virus de la hepatitis B y C y el de VIH. En este sentido los trabajadores de la salud son quienes están más expuestos a sufrir riesgos profesionales de tipo biológico y por objetos punzocortantes. Cabe señalar, que en el presente estudio no se reportaron transmisiones de microorganismos patógenos, a pesar de haberse mencionado 64 accidentes laborales ocurridos en esta población de dentistas del Estado de Nuevo León México; aunque en México existen aislados reportes de estrategias por controlar los accidentes a través de una cultura de prevención (12).

\section{CONCLUSIÓN}

Con base a estos resultados y siendo la Odontología una profesión de alto riesgo, podemos concluir que es de suma importancia que el odontólogo reconozca el protocolo a seguir en caso de accidente, mejorar las capacitaciones y ampliar su cobertura en los odontólogos en materia de normativas de bioseguridad y manejo de residuos peligrosos biológico infecciosos, así como actualizar el conocimiento de infecciones transmitidas por objetos punzocortantes. 


\section{RECOMENDACIONES}

Se recomienda no romper las agujas, no manipular la aguja para separarla de la jeringa y usar pinzas para manipular objetos punzocortantes. Integrando el conocimiento en materia de bioseguridad se podrán reducir los accidentes por objetos punzocortantes y tener una práctica odontológica segura tanto para el prestador del servicio como para el paciente. Por lo que el medio más efectivo para prevenir los accidentes y la trasmisión de patógenos sanguíneos es mediante la prevención primaria como es la implementación de educación al personal de salud y las precauciones universales en las guías clínicas. En México, es necesario reforzar la cultura de prevención sobre todo entre los prestadores de servicios de salud de atención primaria.

\section{AGRADECIMIENTOS}

Al doctor Christian Ernesto Tapia Espinoza por su colaboración y asesoría en esta investigación.

\section{REFERENCIAS}

1. Gunache, H, Menéndez N, Piñera S, Morales C. Riesgo Ocupacional por Exposición a Objetos Punzocortantes en Trabajadores de la Salud. Revista de Medicina Interna y Medicina Crítica. 2006; 3(2): 56-60.

2. Rodríguez Y, Rivero M, Solana L, Pérez K. Nivel de conocimientos y actitud ante el cumplimiento de la bioseguridad en estomatólogos. Revista de Ciencias Médicas. 2012; 18(1). 
3. Centro Nacional para la Prevención y el Control del VIH y el SIDA (CENSIDA). Guía para la atención estomatológica en personas con VIH. Consejo Nacional de Programas Preventivos y Control de Enfermedades. México DF, México: CENSIDA; 2015.

4. Junco R, Oliva S, Barroso I, Guanche H. Riesgo ocupacional por exposición a objetos punzocortantes en trabajadores de la salud. Rev Cub Hig Epidemiol. 2003; 41(1).

5. Collins $\mathrm{CH}$, Kennedy DA. Microbiological hazards of occupational needle stick and "sharps" injuries: a review. J Appl Bacteriol. 1987; May 62(5): 385-402.

6. Adegbaye AA, Moss EB, Soyinka F, Kreiss JK. The epidemiology of needle stick and sharp instrument accidents in a Nigerian hospital. Infect Control Hosp Epidemiol. 1994; 15(1): 2731.

7. Organización Mundial de la Salud (OMS). VIH/SIDA. Ginebra, Suiza: OMS; 2018. Descargado el día 06/03/2018. Disponible en: http://www.who.int/hiv/es

8. Organización Mundial de la Salud (OMS). Hepatitis B. Ginebra, Suiza: OMS; 2018. $\begin{array}{lllll}\text { Descargado e e día } & \text { 06/03/2018. Disponible }\end{array}$ http://www.who.int/mediacentre/factsheets/fs204/es

9. Ruiz, A. R., Fernández, J. R., Principios de Bioseguridad en los servicios estomatológicos. Rev Cient Villa Clara. 2013; 17(2): 49-55.

10. Cázares F, Alveza, M, Pinedo M. Estrés percibido en odontólogos de los Servicios de Salud de Nuevo León. Rev Mex Estomatol. 2017; 4(2): 16-26.

11. Gutiérrez C, Alarcón J, Sánchez S, Carrión M. Prevalencia y factores asociados a heridas punzo-cortantes en trabajadores de salud del primer nivel de atención. Revista Peruana de Epidemiología. 2008; 12(2): 1-9. 
12. Barroso AJ, Camacho MA, Cashat CM, Cornu GL. Accidente con material punzocortante en trabajadores de la salud. Una situación digna de ser revisada. Enfermedades Infecciosas y Microbiología. 2006; 26(1). 